\title{
Patient safety and the prevention of skin and mucosal lesions associated with airway invasive devices
}

\author{
Segurança do paciente e a prevenção de lesões cutâneo-mucosas \\ associadas aos dispositivos invasivos nas vias aéreas \\ La seguridad del paciente y la prevención de lesiones cutáneo-mucosas \\ asociadas con los dispositivos invasivos en las vías aéreas
}

Deisy Mello de Pinto ${ }^{1}$, Estela dos Santos Schons ${ }^{1}$, Josefine Busanello ${ }^{1}$, Valdecir Zavarese da Costa ${ }^{2}$

${ }^{1}$ Universidade Federal do Pampa, Curso de Graduação em Enfermagem, Campus Uruguaiana, Uruguaiana, RS, Brazil.

${ }^{2}$ Universidade Federal de Santa Maria, Centro de Ciências da Saúde, Santa Maria, RS, Brazil.

\begin{abstract}
Objective: To analyze the care implemented by the nursing team to promote the safety of adult patients and prevention of skin and mucosal lesions associated with the presence of lower airways invasive devices. Method: Study with qualitative and quantitative approach, descriptive and exploratory type, whose investigative scenarios were adult inpatient units of a hospital in the West Frontier of Rio Grande do Sul. The study subjects consisted of nurses, nursing technicians and nursing assistants. Results: A total of 118 professionals were interviewed. We highlight the observed specific care with endotracheal tube and tracheostomy, management and assessment of the cuff and the criteria used to secretion aspiration. Conclusion: There is a superficial nursing work in the patient direct care and a differentiation in relation to the perception of nurse technicians, especially those working in the intensive care unit, who presented major property and view of the patient's clinical status.
\end{abstract}

\section{DESCRIPTORS}

Nursing Care; Intubation Intratracheal; Tracheostomy; Pressure; Wounds and Injuries; Patient Safety. 


\section{INTRODUCTION}

Hospitalized patients in clinical units or intensive care units at some point may require the use of an airway device to replace or assist in maintaining ventilation. The use of an endotracheal tube (ET) and/or tracheostomy tube are the main instruments that composes this maintenance, allowing oxygen installation, removal of secretions and mechanical ventilation.

Facing the use of these invasive devices, patients can be subjected to cutaneous and mucosal lesions in upper and lower airways. Thus, we highlight aspects related to patient safety and the onset of these adverse events that may result from the length of use, above all, the list of complex care required to maintain these devices, in which minimum failures can be translated in irreparable damage to the patient.

Patient safety is aimed at reducing unnecessary harm, involving the practical actions that minimize the complications to the context and devices from which care is provided $^{(1)}$. Still, patient safety is related to the actions to ensure the integrity of people, preventing adverse events and the prevention of errors, thus promoting a safer patient care ${ }^{(2)}$.

Thus, care processes that permeate the care of patients who use these devices, especially those airways invasive, should focus on reducing the risk of skin and mucosal, oropharyngeal, laryngopharyngeal, laryngeal and tracheal lesions. These measures ensure the airway maintenance, important for therapy, avoiding possible temporary or permanent damage, longer hospitalizations and, consequently, the patient's suffering.

Considering the security for the prevention of skin and mucosal lesions in patients undergoing lower airways invasive devices, there is little scientific production in Nursing and related areas. However, it is important to rescue this approach, considering that these lesions are directly related to nursing care and can be prevented from the inclusion of actions to ensure patient safety.

Based on the aspects discussed, the present study seeks to answer the following questions: What are the Nursing actions that contribute to the promotion of adult patient safety with lower airways invasive devices? Do these actions favor the prevention of skin and mucosal lesions associated with presence of these devices?

The skin and mucosal lesions associated with orotracheal intubation may be caused from the intubation procedure, that is, early lesions, such as extraction, avulsion of the vocal folds, lesions on the corner of the lips, tongue and throat, tears in epiglottis, vocal cords, esophagus and trachea, tracheal and glottis edema, tracheal ischemia, bruises and tracheitis ${ }^{(3-5)}$. However, most incident injuries are tracheomalacia, tracheal necrosis and stenosis, laryngeal and vocal cords ulcers, paresis and paralysis of vocal cords, tracheoesophageal fistula and granuloma, all related to the greater length of time device use ${ }^{(3,6-8)}$. Furthermore, the intubation procedure can lead to complications in clinical status of patients, including: severe hypoxia, severe hypotension, esophageal intubation, aspiration, cardiac arrest and death ${ }^{(9)}$.

Regarding the lesions caused by the use of tracheostomy, these may occur in the intraoperative period, with unilater- ally or bilaterally laryngeal nerve injury; esophageal injury with tracheoesophageal fistula; and early lesions in the first six days with false path by moving the tracheal tube. Postoperative injuries can also occur, after seven days, such as tracheoesophageal fistula; subglottic or tracheal stenosis; tracheomalacia; tracheocutaneous fistula (after decannulation); and hypertrophic scarring after decannulation ${ }^{(10)}$.

Facing the range of adverse events, we highlight the complexity of nursing care associated with invasive devices. Thus, professionals should have clinical competence and skills to ensure decontamination, hygiene, and proper handling of all devices that involve care to these patients. Furthermore, it is important to recognize the factors that may contribute to the appearance of these lesions and implement actions to prevent these complications.

Thus, we justify the importance and relevance of this study, which proposes to address the care focused on the individual undergoing these invasive devices procedures because Nursing is mainly responsible for managing these instruments and need to be exploited to prevent adverse events. The results of this study may subsidize professional development processes, as well as restructuring standard operating protocols that define the guidelines for patient safety from the prevention of skin and mucosal lesions associated with lower airways invasive devices.

In this sense, the study aimed to analyze the care implemented by the nursing team to promote safety of adult patients and the prevention of skin and mucosal lesions associated with the presence of lower airways invasive devices.

\section{METHOD}

This is a study with a quantitative approach, descriptive and exploratory type. To deepen the analysis we also opted for a qualitative approach. The combination of qualitative and quantitative methods produces a methodological triangulation, which establishes a relationship between complementary opposites, seeking the approximation of positivism and comprehensivism ${ }^{(11)}$.

In this study the qualitative and quantitative triangulation made possible to analyze objectively and subjectively the care implemented by Nursing team to prevent skin and mucosal lesions associated with the presence of lower airways invasive devices, with the theoretical precepts and concepts about patient security presented by international ${ }^{(1)}$ and national ${ }^{(2)}$ agencies.

The investigative study scenario were the adult inpatient units, in clinical specialties, surgery, intensive care and emergency room of a hospital located in the West Frontier of Rio Grande do Sul.

The sample size was composed by 118 Nursing professionals, which corresponds to $77 \%$ of this population. The inclusion criteria was: to work in an adult inpatient unit, described as investigative study scenario. The exclusion criteria was: to be on leave for health reasons or vacation, during the data collection period.

Data collection was carried out through interviews, from November 2013 to January 2014, in an environment defined by the Nursing Coordination from the institution 
during the work shift. The semi-structured interviews followed a script, which was previously validated, with open and closed questions. The interviews were recorded in a MP3 file, which was transcribed, maintaining the integrity of the participants' discourses.

Theoretical frameworks aimed at patient safety within international $^{(1)}$ and national ${ }^{(2)}$ scenarios, allowed the structuring of the study categories of analysis. So for the qualitative data analysis we used thematic analysis ${ }^{(12)}$, consisting of three stages: pre-analysis, material exploration and treatment of results and interpretation. And for quantitative analysis of the data we used the frequency distribution techniques, descriptive analysis, and nonparametric Pearson chi-square, significance level of $5 \%(p<0.05)$, with the help of Statistical Package software for Social Sciences (SPSS) 20.0, available in the Graduate Laboratory of the Universidade Federal do Pampa (UNIPAMPA), Uruguaiana Campus.

The research follows the resolution of the Brazilian $\mathrm{Na}-$ tional Health Council that regulates research involving human subjects. Study participants signed the Consent Form. The project was submitted to the Research Ethics Committee of UNIPAMPA, and it was approved in July 25 $5^{\text {th }}, 2013$, under the protocol number 360967/2013.

\section{RESULTS}

A total of 118 nursing professionals were interviewed, of these $18.6 \%(n=22)$ were nurses, $78 \%(n=92)$ nursing technicians and 3.4\% $(n=4)$ nursing assistants, with female predominance $(80.5 \%-n=95)$. Most participants $(46 \%-n=54)$ worked during the night shift in intercalated shifts. After that, we present the care implemented by the Nursing team to promote the safety of adult patients and prevent skin and mucosal lesions, associated with the presence of lower airways invasive devices.

\section{Specific Care with the orotracheal tube}

Nursing professionals were asked to perform preventive care for lesion and oral fissures in patients who used the orotracheal tube (OT). Approximately 83\% (n=98) stated they performed OT care.

Other professionals who did not perform OT care said they did not attend patients with these devices, considering that the clinical and surgical inpatient units does not usually admit critically ill patients, and when that happens, in those occasional situations, the same professionals are the ones who are responsible for the care of these patients.

I never cared for an intubated patient, during my training course, I was trained for two days in the $I C U$, nothing else, so I know very little about intubated patient (TEC18).

We do not have it here, and when we do, they stay isolated with a colleague (TEC36).

Regarding prevention of fissures and oral lesions in intubated patients, the most common care were: oral hygiene, proper fixation of laces, aspiration, oral hydration, OT position change and protecting the skin from the OT friction. Professionals also reported the importance of lace change, and $72 \%(n=85 \%)$ of professionals performed changes once per shift, and whenever was necessary.

Switching tube, also replacing fixation, I do not let the fixation very tight or I put a protective gauze on the fixation side (NUR20).

We hydrates them (...). The lace, when we always go fix it, we put a protection, a gauze which is closer to the mouth (...). We use some oil, we are careful not to hurt them. In case we see it is dirty, we repeat hygiene, when there is a lot of secretion (TEC54).

Specifically, nursing technicians also had other care actions to prevent fissures and oral lesions in intubated patients: switch and adequacy of the size of guedel airway, care to introduce too much of the probe during aspiration, inflating and deflating the balloon, and routine aspiration to avoid OT blockade.

My patients usually don't have a tube. There is this tube cuff, then when I was with a clinical patient, we inflated and deflated the cuff to prevent lesion to the trachea, (...) lace change (TEC09).

\section{(...)Being careful when we do aspiration and also in oral bygiene. (...) The lace (...), the tube itself, I'm very careful when I insert, in the aspiration part, because you can introduce more than you should and cause more internal damage (TEC50).}

The following care procedures for the prevention of oral lesions were also presented to the professionals: moisturizing lip, lace change, oral hygiene, change in position of OT and protection of lips (gauze) against the friction of the OT. Approximately 40\% ( $n=9)$ of nurses consider changing OT position in the oral cavity as the most important behavior to avoid oral lesions and fissures associated with OT, and about $37 \%(n=34)$ of nursing technicians consider as a preventive measure to protect the lips (gauze) against the friction of the OT $(\mathrm{p}=0.038)$.

The prevention of accidental extubation is part of care according to $80 \%$ ( $n=94 \%$ ) of professionals. Regarding care to prevent accidental extubation the following actions were presented: adequate fixation with laces, adequate cuff pressure, positioning and containment of the patient. Over $36 \%(n=42)$ of the professionals related to containment, and $34 \%(n=40)$ of the professional to proper fixation of lace as the most important care to prevent accidental extubation and prevent skin and mucosal lesions associated with this adverse episode.

\section{Tracheostomy Specific Care}

Over 97\% $(n=114)$ of the professionals reported to perform care for injury prevention in patients using tracheostomy. The most highlighted care by professionals for injury prevention in patients using tracheostomy were: performance of the dressing and changing the lace, professional duties performed once a shift and whenever there is a need for more than $80 \%(n=94 \%)$ of professionals, and protection with gauze around the tracheostomy. 
The daily hygiene every shift, dressing change, that is, a small gauze around it, clean, that's it (NUR15).

External is the lace, sometimes too much tightening, the gauze around the 'tracheo' cleaning there, hygiene once per shift and aspiration, sometimes they aspire too much, then the patient is harmed (TEC66).

Always replacing the lace not to get dirty, always protecting with gauze underneath, removing the endotube, hygiene once per shift, aspiration and suction so it does not cover the "tracheo"(ASS 88).

Regarding the material used for the tracheostomy dressing, $72 \%(n=85)$ reported to use $0.9 \%$ saline solution, and $24.6 \%(n$ $=29$ ) used aqueous chlorhexidine. Professionals also highlighted care for aspiration, such as: aspiration only when necessary, inserting the tube with care, and liquefy secretions.

Mainly being careful with aspiration, not intro-
ducing the tube too much, measuring it, fluid-
izing with saline solution. In the dressing use
gauze and saline solution (...) (NUR77).
Protection with gauze, and also what it is rou-
tine, we use mineral oil, without aspiration sev-
eral times, unless the patient has a lot of secre-
tion, avoiding suction too often (TEC75).

Nurse technicians active in clinical, surgical and intensive care units, reported to be in permanent contact with tracheotomy patients, highlighting other Nursing care: hygiene of endotube, using two laces to fix the tracheostomy, moisturizing the skin with oil, protection use in the neck around the laces and the non-fixing of dressing with micropore or tape. More than $80 \%$ of professionals perform the lace switching once a shift, and when necessary.

Providing good hygiene, aspirating according to
the needs of the "tracheo patient" clean endotube,
observing the catheter quantity that is using to
aspirate, for no mucosal lesions, even the inner-
most and also to protect the laces, do not injury,
hurt neck, face (...) (TEC 89).

Some nursing technicians and a nurse reported they did not perform tracheostomy care because they did not work with patients who used these devices.

Here in the ER we hardly admit patients who need to use the "tracheo", it is very difficult (NUR 31).

It is not my routine (TEC41).

\section{Cuff Care}

Regarding the assessment of OT cuff pressure and tracheostomy, more than $40 \%(n=47)$ of the technicians and nursing assistants claim to perform them. The same percentage associated with nurses $(n=9)$, result with statistical significance $(p=0.756)$. Almost all nursing technicians who work in the ICU check the cuff pressure.
When asked about the assessment criteria of the cuff pressure, the responses varied according to the workplace. Verification with endotracheal tube cuff-pressure monitor was reported by four nurses (two ICU and two from the clinical and surgical units). Only two Nursing technicians working in the ICU cited the use of this instrument for checking the cuff pressure.

We can do this because (...) now we have this instrument. We do it with technique, not like before, before the instrument we had to make an average, sort of(...) and inflate the cuff (TEC47).

Now the ICU is providing an endotracheal tube cuff-pressure monitor for us. Then once per shift pressure is verified. (...) is the values are from 15-35, we check if it is in the interval, then we can deflate or inflate more (TEC43).

Regarding the frequency of assessing the cuff pressure, most professionals refer to perform at least once a shift, as well as medical advice.

As the doctor's request (NUR40).

Once per shift at least (NUR77).

I arrive and check everything (...) make a general check and see if it is too inflated, deflate a little, especially when it has an escape (TEC61).

The other Nursing technicians reported not using the endotracheal tube cuff-pressure monitor due to the lack of knowledge to handle such an instrument, and considering that this is an assignment of the nurse or doctor.

(...) I was helping my colleague and then she deflated it, then inflated back if I am not mistaken with $20 \mathrm{ml}$, then, that's what I saw, I cannot tell you, 'Oh, I know more things', because I do not. (...) In general who does these procedures are the doctors here at the hospital. It happened that day because the doctor trusted the nurse to do it (...). It is on 'lucky', 'guess' (NUR14).

Yes, I don't know (...) deflate and inflate the cuff? Then I asked $5 \mathrm{ml}$, but she felt bad (...) the doctor put $2 m l$ and a half. (...) We do this with the syringe. I do not know if they have the 'gadget', Inever heard it (TEC18).

The other methods for verification of cuff pressure cited by the professionals were digital palpation of the external cuff and use of improvised aneroid gauge. Digital palpation was cited by two nurses of clinical and surgical units, and 34 nurse technicians, the majority were ICU workers.

We don't have the 'gadget' here, but we use what's prepared, which is the 'sphygmomanometers', with the clock from 'sphygmomanometer' (...) (NUR103).

By digital palpation every time that will make up the aspiration to note that it is not having air loss and not let deflate the cuff(TEC79). 
It was also reported by nurses and nurse technicians of the clinical and surgical units the maneuver to inflate and deflate the cuff as medical orientation without using endotracheal tube cuff-pressure monitor or aneroid manometer.

(...) We assess with syringe, we check what has been inflated, thus, as oriented by the doctor the amount that we can inflate (NUR15).

I do not assess because I do not have the habit of evaluating when the doctor prescribes, ask to deflate and check the signals and then inflate again, only at this situation (TEC08).

\section{Care WITH THE ASPIRATION OF THE lOWER AIRWAYS}

Approximately 98\% $(n=115)$ of participants say that they assess the need for aspiration of intubated patients. Others said they did not make that assessment, and/or perform medical prescription.

Some professionals perform aspiration in patients as needed and not according to the routine of the unit. This finding was observed more frequently among ICU Nursing technicians.

We see the patient breathing pattern, if there is no need for aspiration, we do not aspirate frequently to avoid damage to the patient trachea. So when they have a lot secretion, we already know (...) we control the saturation (...) measures the saturation, along with breathing pattern (...)(TEC43).

Considering the criteria used to assess the need for aspiration, professionals highlighted the visualization of the increased amount of secretion in the OT or tracheostomy, altered breathing pattern, and the decrease in oxygen saturation percentage.

I evaluate (...) if the patient is having trouble breathing or is saturating down, and/or we see that the secretion is there in 'tracheostomy', coming out, we see the need to aspire it. When we don't see that much secretion, but we see that the patient is breathing hard and oximetry is decreasing, then we aspirate and the saturation improves and then we are relieved (ASSIS10).

Pulmonary auscultation was cited by two nurses of clinical and surgical units and only for one ER nursing technician.

It depends on the amount of secretion, lung auscultation, respiratory distress of the patient (NUR40).

In addition to the previous data, we presented to the participants the criteria for assessing the need for aspiration of OT and tracheostomy: oxygen saturation, respiratory rate and breathing pattern, auscultation and secretion view in OT and/or tracheostomy. Almost 40\% ( $n=9)$ of nurses chose as criterion for aspiration the frequency and breathing pattern, and most of the nursing technicians (39.1\%$\mathrm{n}=36$ ) cited the secretion view in OT and tracheostomy. Only $22.7 \%(n=5)$ of nurses and $3.3 \%(n=3)$ of the nursing technicians mentioned to perform auscultation $(\mathrm{p}=0.051)$.

\section{DISCUSSION}

To prevent damage and to promote patient safety, planning structures and work processes must be designed and redesigned, as ignorance and lack of protocols are common causes of human error ${ }^{(9)}$. These instruments are effective barriers to the occurrence of errors, or minimizing their likelihood, and the risk of harm to the patient ${ }^{(2)}$.

Fissures and oral lesions may arise in patients who use invasive devices in the airway, by long stay of OT, or inadequate assistance of the Nursing team. A study in two Intensive Care Units of two hospitals in southern Brazil sought to know the experiences of patients who used invasive mechanical ventilation, and they mentioned that the presence of the artificial airway causes difficulties and needs, such as presence of oral lesions arising from the endotracheal tube ${ }^{(5)}$. In this research, most nursing professionals have knowledge of the risk factors for the emergence of these injuries, and perform care for oral injury and fissures prevention in patients who use OT.

Patient safety using OT can be guaranteed from the complications monitoring of aspiration, closed aspiration system, not the use of saline instillation consistently, hydration of the oral mucosa and lips ${ }^{(13)}$.

One of the actions for the prevention of lesions of the oral cavity is associated with an effective oral hygiene which must be performed with oral $0.12 \%$ chlorhexidine, with a small sponge, avoiding cavity lesions, three or four times a day. Thus, it is possible to eradicate bacterial colonization, and provide a reduction in the incidence of mechanical ventilator-associated pneumonia ${ }^{(2,14)}$.

All these precautions should be included in the established nursing prescription from the nurse's assessment of the maintenance and management of invasive devices. Within the prescription, the most appropriate form of oral hygiene for the patient should be included, considering their medical condition, risk of bleeding, presence of lesions in the oral cavity, mouth opening, level of sedation/ awareness, presence or absence of teeth, tubes and probes ${ }^{(15)}$.

The intense involvement of the Nursing professional in patient care makes it the main subject of adverse events. In the presence of OT, one of the main harmful situations is accidental extubation ${ }^{(16-17)}$. Several situations may contribute to the occurrence of this event, such as: bath in bed, transportation, proper fixation and change of decubitus, requiring special attention of the team at the time of the procedures ${ }^{(18)}$. These aspects were not reported by the study participants, who highlighted the need for restraint to prevent accidental extubation ${ }^{(19)}$.

With regard to the tracheostomy, it is emphasized that the dressing should be performed with sterile gauze pad around the tube and should be changed daily and whenever necessary. The tracheostomy tube should be fixed by a clean tape inserted in the side opening of the outer tube and by fixing the tape, put two fingers in the inside part to prevent strangulation, and leaving it comfortable for the patient ${ }^{(20)}$.

Almost all researched professionals assess somehow the need for aspiration of patients with OT or tracheostomy. The 
aspiration of invasive devices and airway should be performed only when there are suggestive signs of the presence of secretion, such as suggestive sound on auscultation, visible secretions in the invasive device and jagged pattern on the flow-volume curve observed in the ventilator screen $^{(21-22)}$. In addition, the decrease in tidal volume during ventilation with pressure or deterioration of oxygenation demonstrated by the decrease in O2 saturation is also a signal indicative of the need for aspiration ${ }^{(22)}$. The aspiration procedure should follow the following actions: latex occlusion; careful introduction of the probe; aspiration for 3 to 5 seconds; and slow retreat of the probe in a circular motion, noting for signs of hypoxia and arrhythmias ${ }^{(20,23)}$.

Participants highlighted the liquefication of secretion at the time of aspiration. This is in extensive discussion in the literature, there are numerous contradictions and lack of evidence on the precise benefits of using $0.9 \%$ saline solution in endotracheal aspiration. Given this scenario, it is not recommended for routine use, being available to the management of secretions which are difficult to remove, as in the case of thick secretions and mucous plugs ${ }^{(23)}$.

The skin and mucosal lesions caused by the use of endotracheal tube and tracheostomy are dependent on several factors such as the patient's clinical conditions, prolonged length and inadequate care provided by the Nursing team.

More than half of nursing professionals did not perform measures of the cuff pressure of patients who are intubated or tracheostomy. The high percentage of professionals who did not perform it can be associated to lack of endotracheal tube cuff-pressure monitor, ignorance or lack of concern with regard to possible complications caused by not checking and assess the cuff( ${ }^{(24)}$. Most professionals using the method of digital palpation, which does not provide the measurement precision of the cuff pressure ${ }^{(3,25)}$.

Although they do not use the appropriate measurement method, the professional do it once a shift, which is consistent with the guidelines of the area ${ }^{(21)}$, which recommends the measurement of cuff pressure performed at least three times a day. In this research, the professionals working in the ICU were highlighted, because they are directly in contact with patients with airways invasive devices.

The prevention of cutaneous and mucosal lesions is an ongoing concern in patients using airway devices, especially with respect to bacterial colonization. Two care practices, such as raising the head of the bed at an angle of 30 degrees or more, and the use of OT in a continuous extraction system with lumen above the cuff, allowing for subglottic aspiration, demonstrated success in reducing bacteria colonization rates ${ }^{(13)}$.

Other adverse events regarding the use of devices and equipment are related to the complexity and variety of devices, manufacturers, specifications and operating techniques of each device ${ }^{(2)}$. In this sense, we highlight the importance of Nursing staff instrumentation to face the intricate set of peculiarities that involve patient care with airway invasive device.

\section{CONCLUSION}

The main contribution of the study, compared with other scientific studies on the subject, is to draw attention to the nurse's role superficiality in direct patient care. Specifically, in this study, we observed that the role of the nurse is increasingly distant from the clinical evaluation process and interventions for patients with airway invasive devices.

The care differs according to service unit and profession category. This distinction is not linked to the care technics, but the different perceptions of Nursing technicians - especially those working in the intensive care unit, which had greater property detail and clinical view of the patient. This perspective is very positive for the health care context. However, the question is: What is the role of the Nurse facing the Nursing care?

Among the advances of the study, we highlight the proposal to discuss the rescue of the Nurse's position in decision-making and practical interventions in patient direct care. This scenario can be established from the development of protocols and professional development, focusing on promoting safety of adult patients and prevention of skin and mucosal lesions associated with the presence of invasive devices in the lower airways.

It should be noted that patients who make use of airway invasive devices can remain both hospitalized in ICUs as in clinical and surgical units, so the nursing staff should be instrumentalized for this care, thus, promoting patient safety.

Considering care specificities with endotracheal tube, actions performed by nursing staff who are not referred to in the literature to inflate and deflate the cuff were evidenced, considering a medical determination. This result reinforces the importance of nurses to assume their role in the care that is within their competence and spread to their team in order to prevent skin and mucosal lesions.

The results on the evaluation of OT cuff pressure or tracheostomy are worrying because professionals did not demonstrate knowledge of how this device can cause lesion to the patient. Regarding the tracheostomy specific care, the survey shows that professionals have more contact with this device and therefore, care is more effective, being show in scientific research.

The secretion aspiration is a procedure that needs special attention in the professionals' improvement process. In addition, there is the need for more research focused on the criteria used for aspiration, because with this study we could not define how professionals performed the procedure. It was noted that a limited number of professional uses auscultation as a criterion to assess the need for aspiration, this criterion is considered of fundamental importance in assessing the necessity of the procedure.

The scarcity of studies on this theme relating to promoting patient safety with prevention of skin and mucosal lesions is noteworthy. Thus, it is expected that this study subsidize new research and contribute to the improvement of care, promoting patient safety and prevention of skin and mucosal lesions.

The results of this study provide subsidies for the institution researched, for decision-making and interventions to the practice of care, elaborating care protocols and prevention, including development of activities focusing on this topic. Thus, strengthening the education and practice of care, improving care and ensuring patient safety and the prevention of skin and mucosal lesions. 


\section{RESUMO}

Objetivo: Analisar os cuidados implementados pela equipe de Enfermagem para a promoção da segurança do paciente adulto e a prevenção de lesões cutâneo-mucosas associadas à presença de dispositivos invasivos nas vias aéreas inferiores. Método: Estudo com abordagem qualitativa e quantitativa, do tipo descritivo e exploratório, cujos cenários investigativos foram as unidades de internação adulto de um hospital da Fronteira Oeste do Rio Grande do Sul. Os sujeitos pesquisados constituíram-se de enfermeiros, técnicos e auxiliares de Enfermagem. Resultados: Foram entrevistados 118 profissionais. Evidenciaram-se os cuidados específicos com o tubo orotraqueal e traqueostomia, com o manejo e avaliação do cuff e os critérios utilizados para a aspiração de secreções. Conclusão: Há uma superficialidade da atuação do enfermeiro no cuidado direto ao paciente e uma diferenciação em relação à percepção dos técnicos de Enfermagem, em especial os atuantes na unidade de terapia intensiva, que apresentaram maior propriedade e visão da clínica do paciente.

\section{DESCRITORES}

Cuidados de Enfermagem; Intubação Intratraqueal; Traqueostomia; Pressão; Ferimentos e Lesões; Segurança do Paciente.

\section{RESUMEN}

Objetivo: Analizar los cuidados implantados por el equipo de Enfermería para la promoción de la seguridad del paciente adulto y la prevención de lesiones cutáneo-mucosas asociadas con la presencia de dispositivos invasivos en las vías aéreas inferiores. Método: Estudio con abordaje cualitativo y cuantitativo, del tipo descriptivo y exploratorio, cuyos escenarios investigativos fueron las unidades de estancia hospitalaria de adultos en un hospital de Fronteira Oeste, Rio Grande do Sul. Los sujetos investigados se constituyeron de enfermeros, técnicos y auxiliares de Enfermería. Resultados: Fueron entrevistados 118 profesionales. Se evidenciaron los cuidados específicos con el tubo orotraqueal y la traqueotomía, con el manejo y la evaluación del cuffy los criterios utilizados para la aspiración de secreciones. Conclusión: Existe una superficialidad de la actuación del enfermero en el cuidado directo al paciente y una diferenciación con respecto a la percepción de los técnicos de Enfermería, en especial los actuantes en la unidad de terapia intensiva, que presentaron mayor propiedad y visión clínica del paciente.

\section{DESCRIPTORES}

Atención de Enfermería; Intubación Intratraqueal; Traqueotomía; Presión; Heridas y Traumatismos; Seguridad del Paciente.

\section{REFERENCES}

1. World Health Organization. World Alliance for Patient Safety. Forward Program 2006-2007. Disponível em: http://www.who.int/ patientsafety/information_centre/WHO_EIP_HDS_PSP_2006.1.pdf

2. Brasil. Ministério da Saúde. Agência Nacional de Vigilância Sanitária. Manual segurança do paciente e qualidade em serviços de saúde: uma reflexão teórica aplicada a prática. Brasília: MS; 2013.

3. Stanzani VL, Ribeiro R, Silva ES, Pinto WM. Conhecimento teórico-prático da equipe assistente sobre manejo e pressão do balonete endotraqueal. ConScientiae. 2009;8(1):25-34.

4. Mota LAA, Carvalho GB, Brito VA. Complicações laríngeas por intubação orotraqueal: revisão da literatura. Int Arch Otorhinolaryngol. 2012;16(2):236-45.

5. Dornelles C, Oliveira GB, Schwonke CRGB, Silva JRS. Experiências de doentes críticos com a ventilação mecânica invasiva. Esc Anna Nery. 2012;16(4):796-801.

6. Coelho MS, Stori Junior WS. Lesões crônicas da laringe pela intubação traqueal. J Pneumol. 2001;27(2):68-76.

7. Martins RHG, Dias NH, Santos DC, Fabro AT, Braz JRC. Aspectos clínicos, histológicos e de microscopia eletrônica dos granulomas de intubação das pregas vocais. Rev Bras Otorrinolaringol. 2009;75(1):116-22.

8. Servin SON, Barreto G, Martins LC, Moreira MM, Meirelles L, Colli Neto JA, et al. Atraumatic endotracheal tube for mechanical ventilation. Braz J Anesthesiol. 2011;61(3):311-9.

9. Nolan JP, Kelly FE. Airway challenges in critical care. Anaesthesia. 2011;66(2):81-92.

10. Ricz HMA, Mello Filho FV, Freitas LCC, Mamed RCM. Traqueostomia. Medicina (Ribeirão Preto). 2011;44(1):63-9.

11. Brügemann OM, Parpinelli MA. Using quantitative and qualitative approaches in knowledge production. Rev Esc Enferm USP. 2008;42(3):563-8.

12. Minayo MCS. O desafio do conhecimento: pesquisa qualitativa em saúde. 10a ed. São Paulo: Hucitec; 2010.

13. Siela D. Evaluation standards for management of artificial airways. Crit Care Nurse. 2010;30(4):76-8.

14. Shi Z, Xie H, Wang P, Zhang Q, Wu Y, Chen E, et al. Oral hygiene care for critically ill patients to prevent ventilator-associated pneumonia. Cochrane Database Syst Rev. 2013;(8):CD008367.

15. Orlandini GM, Lazzari CM. Conhecimento da equipe de enfermagem sobre higiene oral em pacientes criticamente enfermos. Rev Gaúcha Enferm. 2012;33(3):34-41.

16. Nascimento CCP, Toffoletto MC, Freitas WG, Padilha KG. Indicators of healthcare results: analysis of adverse events during hospital stays. Rev Latino Am Enfermagem. 2008;16(4):746-51.

17. Paiva MCMS, Paiva SAR, Berti HW, Campana AO. Characterization of patient falls according to the notification in adverse event reports. Rev Esc Enferm USP. 2010;44(1):134-8.

18. Castellões TMFW, Silva LD. Ações de enfermagem para a prevenção da extubação acidental. Rev Bras Enferm. 2009;62(4):540-5. 
19. Tanios MA, Epstein SK, Livelo J, Teres D. Can we identify patients at high risk for unplanned extubation? A large-scale multidisciplinary survey. Respir Care. 2010;55(5):561-8.

20. Silveira LSS, Oliveira MAC, Martins CK. Assistência do enfermeiro no pós-operatório de traqueostomia realizada na UTI. Littera [Internet]. 2013 [citado ago. 15];2(3). Disponível em: http://www.litteraemrevista.org/ojs/index.php/Littera/article/view/77/92

21. Jerre G, Silva TJ, Beraldo MA, Gastaldi A, Kondo C, Leme F, et al. Fisioterapia no paciente sob ventilação mecânica. J Bras Pneumol. 2007;33 Supl 2:142-50.

22. Martins I, Gutiérrez MGR. Intervenções de enfermagem para o diagnóstico de enfermagem desobstrução ineficaz de vias aéreas. Acta Paul Enferm. 2005;18(2):143-9.

23. American Association of Respiratory Care. AARC Clinical Practice Guidelines: endotracheal suctioning of mechanically ventilated patients with artificial airways 2010. Respir Care. 2010;55(6):758-64.

24. Peña ELC, Gregori WM, Piccinini Filho L, Vieira JE, Mathias LAST. Determinação de volumes e pressões de balonetes de tubos traqueais insuflados com ar ambiente ou óxido nitroso. Rev Bras Anestesiol. 2004;54(3):335-42.

25. Muñoz VE, Mojica S, Gómez JM, Soto R. Comparación de la presión del manguito del tubo orotraqueal estimada por palpación frente a la medición tomada con un manómetro. Rev Cienc Salud. 2011;9(3):229-36. 